\title{
A Traceability Public Service Cloud Platform Incorporating IDcode System and Colorful QR Code Technology for Important Product
}

\author{
Shaqing Zhang $\mathbb{D}^{1,2}$ Jinhui Liao ${ }^{10}{ }^{1}$ Shuangcheng $W u\left(\mathbb{D},{ }^{1}\right.$ Junrui Zhong $\mathbb{D}^{3}$, \\ and Xiaoping Xue $\mathbb{D}^{4}$ \\ ${ }^{1}$ School of Management, Guangdong University of Technology, Guangzhou 510520, China \\ ${ }^{2}$ Huizhou Guangdong University of Technology IoT Cooperative Innovation Institute Co., Ltd., Huizhou 516025, China \\ ${ }^{3}$ Information Center, The First Affiliated Hospital of Jinan University, Guangzhou 510630, China \\ ${ }^{4}$ School of Information Engineering, Huizhou Economics and Polytechnic College, Huizhou 516057, China
}

Correspondence should be addressed to Junrui Zhong; ecis@163.com

Received 17 January 2021; Accepted 19 May 2021; Published 8 June 2021

Academic Editor: Aijun Liu

Copyright ( $\odot 2021$ Shaqing Zhang et al. This is an open access article distributed under the Creative Commons Attribution License, which permits unrestricted use, distribution, and reproduction in any medium, provided the original work is properly cited.

At present, the epidemic situation of COVID-19 is raging rampantly in the whole world, affecting the hearts of billions of people. The new coronavirus has been detected in many foods and agricultural products. At the same time, vaccines and medicines to prevent or treat COVID-19 are also stepping up research and development and gradually put into use. The quality and safety of foods, medicines, and agricultural products are directly related to the lives and health of people. There are many potential dangers and hidden risks of accidents in the production, sale, and transportation of dangerous goods and special equipment. Therefore, it is necessary to effectively monitor and record the workflow of the above productions or goods. In this paper, we developed an important product traceability public service cloud platform (IPTPSCP) based on batch identification and record keeping with International Two-Dimensional Code Object Identifier System (IDcode) coding rules. Through a case study of the tea factory that produces and sells Xinyang Maojian tea, a test and implementation of IPTPSCP was shown by designing a colorful QR code to prevent the traceability information from being forged in batches. Judging from the overall effect of the practical application of more than a dozen settled enterprises, IPTPSCP has improved the efficiency of data collection and monitoring by about $13 \%$. The results show that the IPTPSCP can be considered as an effective tool to guarantee the quality and safety of products. Besides, since it is not required for the enterprise to invest much money and manpower to develop software, IPTPSCP reduces the cost of implementing product traceability by about $36 \%$.

\section{Introduction}

In the current global market, product quality has increasingly become an important factor influencing the customers' purchase intention. However, there are still a large number of fake products on the market. Serious harm to the interests of consumers from product liability accidents continues to occur, such as recent outbreaks of stained milk powder and mad cow disease in the food industry [1] and incidents of problematic vaccines and bogus drugs in the pharmaceutical industry [2]. The dissemination of these hugely influential negative events through the media has caused consumers to gradually reduce their trust in the products and increased consumers' concerns about the source of the products [3]. Thus, with the increasing public awareness of product safety, consumers' increasing demand for high-quality products has led them to pay increasing attention to and support for traceable products [4]. In the current environment where COVID-19 is raging around the world, people are particularly looking forward to high-quality, traceable, and anticounterfeit foods, medicines, vaccines, etc. However, due to the information asymmetry in the market, product adulteration and shoddy products frequently occur, triggering the outbreak of a crisis of market confidence, which may eventually lead to market failure [5, 6]. A traceability system is an efficient tool that can monitor the quality of the products and reduce the 
information asymmetry of adverse selection and moral hazard in product systems. The application of a traceability system is therefore of great strategic importance to achieve continuous quality improvement [7]. And EPC (Electronic Product Code), RFID (Radio-Frequency Identification), 2D barcodes $(\mathrm{QR}, \mathrm{VC}$, and $\mathrm{DM})$, and other technologies are increasingly used in traceability systems [8-11].

The frequent occurrence of various product quality and safety incidents has also aroused the concerns of the public departments of many countries and prompted them to actively implement corresponding intervention measures [12]. At present, the European Union has established the legal framework and technical support system for food safety traceability with "Regulation 178-2002" at its heart. With the Bio-Anti-Terrorism Act and the Food Safety Modernization Act as the core, the United States has also set up a food safety traceability legal system. By successively promulgating and improving the People's Republic of China Law on Quality and Safety of Agricultural Products, the Food Safety Law of the People's Republic of China, and other legal provisions, China has made great progress in establishing a legal system of traceability. In particular, it should be pointed out that China issued and implemented six national standards for important product traceability on October 18, 2019. These standards are primarily intended to solve the basic common requirements such as terminologies that urgently need to be standardized and system construction, as well as meet data interconnection, information collection, and other key technical requirements in the construction of traceability systems for important products including agricultural products, foods, medicines, agricultural production materials, special equipment, dangerous goods, and rare earth products. It is clear that the publication and implementation of the six national standards will effectively improve the standardization of the construction and management of important product traceability systems. Moreover, ZIIOT (Zhongguancun Industry and Information Research Institute of Two-Dimensional Code Technology) in China independently developed the IDcode coding system, which is applied to carry out the global unique two-dimensional code identification for any type of object (person, thing, and item). IDcode, which features flexible layering, good compatibility, and strong scalability, is suitable as a meta-identification mechanism for exchanging existing coding systems [13].

This paper aims to establish an important product traceability public service cloud platform (IPTPSCP) by combining IDcode coding rules and colorful QR code technology applications. The main contributions of this paper are as follows:

(1) Using the IDcode coding system, a public service platform for traceability of important products based on the cloud computing model is developed. It can flexibly customize the process and granularity of product traceability for different products and different user needs, which reduces the cost of platform development and improves the application efficiency of the platform.

(2) A colorful QR code is developed. Compared with ordinary black and white QR codes, it is much more difficult for colorful QR codes to be forged in batches, thereby greatly improving the security of the traceability platform.

The remainder of the paper is structured as follows. In Section 2, a literature review is presented. In Section 3, the system analysis for IPTPSCP is elaborated. Then, in Section 4 , the system design and implementation of IPTPSCP are defined in detail. Section 5 is dedicated to a case study for testing and evaluating the feasibility and effectiveness of IPTPSCP. Finally, conclusions and further research subjects are presented in Section 6.

\section{Literature Review}

At present, scholars from various countries have conducted a great deal of fruitful research on traceability. Different definitions of traceability can be derived from various legislations, standards, and scientific literature. Olsen and Borit analyzed and summarized many definitions of traceability. They claimed that traceability refers to the ability to access any or all information related to the information under consideration over the entire life cycle through the identification of the record [14]. Meo stated that traceability in food production can be tracked from the inside of the manufacturing plant to the whole or part of the production chain from raw materials to customers [15]. As an important subsystem of quality management, the early traceability system can work normally on the basis of pen and paper records. However, as food regulations become increasingly perfect, simple traceability mechanisms in the food industry have become growingly advanced. Traceability must be handled by the establishment of similar systems. A growing number of companies are beginning to realize the benefits of traceability systems. The application of the system forces the company to comply with mandatory regulations and promotes the company's products to pass international standards and certification requirements. The implementation of the system can help companies to improve marketing efficiency and ensure product sources and product quality. In addition, the benefits of the system include product valueadded, anticounterfeiting features, lower inventory levels, lower labor costs, improved operation plans, logistics efficiency, etc. In addition, in the face of health incidents, the systems enable enterprises to have good response capabilities [16-18]. In recent years, various regions and relevant departments in China have actively promoted the application of modern information technology, such as IoT and cloud computing, to establish traceability systems for important products such as agricultural products, foods, medicines, and rare earth. These works and outcomes have shown positive results in enhancing corporate quality management capabilities, promoting innovation in regulatory methods, and ensuring consumer safety [19].

On the one hand, from the point of view of quality management, the real-time monitoring of key environmental parameters through integrated sensors is considered an important method for the effective controlling of product quality. Wang et al. studied the mechanism and knowledge 
flow of the peach export chain and built a real-time tracking and traceability framework for peaches [20]. Multiple sensors have been used to record key environmental parameters in the peach export chain. The system ensures that the quality and protection of peaches and other main links are controlled. Qi et al. used WSN as a simple network infrastructure and developed a retraceability system for aquaculture with robust decision support functions [21]. It can be deployed rapidly to obtain water temperature, salinity, dissolved oxygen, $\mathrm{pH}$, etc., and to realize real-time data transmission. Alfian et al. developed a traceability system for the Korean Kimchi supply chain, which is similar to the peach traceability system proposed by Wang. Both systems used a multisensor network to collect key environmental parameters. The Kimchi traceability method uses a significant amount of data gathered for data mining to make up for missing data and implement data prediction. And RFID technology was used to record and read data to improve work efficiency [22]. Combined with the meat quality of the cold chain and the environmental information collection program, Peng et al. presented a QR code-based tracing method for a quality tracing system [23]. Gao et al. developed an Internet of Things- (IoT-) based intelligent fish farming and tracking control system that includes a forecasting method that enables automatic water quality management and supports tracking the breeding and selling of freshwater fish [24]. Hu et al. first leveraged the immutability of block-chain and the paradigm of edge computing to construct a trust framework for the organic agricultural supply chain, which makes affordable traceability solutions for those in developing countries at a low cost [25].

On the other hand, from the point of view of product supervision and traceability, information recording of key production nodes of products has become the main direction of research. Karlsen et al. proposed that the supply chain of farmed salmon should have different traceability granularities, set up different traceability granularity according to different levels within the company and between the supply chains, and used the GS1 standard for coding for traceability units with different traceability granularity [26]. The Global Trade Commodity Code (GTIN) coding framework and UML class diagrams were used to model the production, processing, and quality information of the vegetable supply chain, with which the quality traceability information and the key information framework of activity participants in the vegetable supply chain were clearly described. The model verification shows that the accuracy of data collection, quality analysis, and inventory management has been enhanced to varying degrees after the application of the traceability system [27]. Thakur and Donnelly constructed a conceptual flow chart for planting, processing, and other links in the soybean value chain and determined the information entry point through information modeling. The traceability code based on the unique identification principle in the Trace Food framework was set up, and different traceable units in different links were determined. Then, a standardized list of data elements was created for mixed operation of different batches of the same type of soybeans, and the electronic information exchange technology in the supply chain was discussed [28]. Qian et al. designed the raw material batch code and the traceability batch code through the analysis of the wheat flour supply chain details. They associated the traceability code with the production information and used QR codes and RFID to record and read information and developed a wheat traceability system to achieve the traceability of bulk wheat flour [19]. Chen et al. developed a mobile pork products quality and safety traceability system based on batch identification and record keeping with two-dimensional codes and reduced the cost of the traceability system [29]. Liang et al. developed the foodgrade grain tracers which is an identification technology for tracing from original harvest to final destination. And automatic separation and identification equipment was designed to implement online production operation for food-grade grain tracers by QR code scanning and information recording [30]. Cai et al. integrated $\mathrm{QR}$ code with quality data and mobile intelligent technology to develop a convenient query terminal for tracing quality in the whole industrial chain of TCM (traditional Chinese medicine) [31]. Li et al. proposed a novel two-sided matching model based on dual hesitant fuzzy preference information to solve the fuzziness and uncertainty of preference information in the matching process of complex product manufacturing tasks on the cloud manufacturing platform, which provided an effective method for supplier selection in the product traceability system [32].

In addition, some scholars study the substances contained in the product itself for traceability of products. Chemical approaches, biomolecular approaches, and isotopic approaches have been used to detect these substances. Fernandes et al. classified red meat with the aid of the study of trace factors in beef to achieve the traceability of Brazilian pork [33]. Bong et al. used a range of elements and isotopes to investigate the geographical origin of Korean beer and measured the element and isotope composition of beer to identify geographical variations [34]. Zhao et al. measured and analyzed the concentrations of 20 elements in samples of tea and soil. The findings have shown that elemental fingerprinting profiles are of obvious difference for tea leaves and provenance soils from different regions [35].

Based on the above literature review, several observations can be obtained. Firstly, the vast majority of traceability systems were developed by manufacturing companies to achieve the traceability of their specific products, and companies need to invest more capital and labor costs for this. However, for different types of products or even different products of the same kind, the key points of traceability and the traceability mechanism could be entirely different. This type of traceability system therefore has poor flexibility and scalability. Secondly, the coding systems or coding rules currently adopted in various traceability systems are different, and a unified standard has not yet been formed, which is not conducive to information sharing and dissemination. Therefore, it is of considerable significance for both academia and industry to explore and develop an IPTPSCP with the most widely used coding and identification standards in the world. 


\section{System Analysis}

3.1. The Survey Design and Analysis. This paper adopted a variety of methods to acquire user needs, including literature collection, policy research, on-site investigation, and interviews.

Firstly, we collected information on the development and application of relevant traceability and anticounterfeiting information systems at home and abroad in recent years, analyzed the characteristics and deficiencies of these systems, and used them as a reference for the system to be developed in the future.

Secondly, we investigated the relevant policies issued by relevant Chinese government departments in the area of important product traceability and anticounterfeiting in recent years and learned that the government's attitude is to encourage third-party organizations to develop and implement important product traceability public service cloud platforms, and they have provided some specific guidance specifications, relevant standards, and requirements.

Thirdly, we have conducted on-site investigations on six enterprises that produce food, drugs, agricultural products, chemical products, dangerous goods, and clothing products in some cities in China, such as Guangzhou, Foshan, Shantou, and Xinyang, and learned about their common or specific requirements for traceability and anticounterfeiting in products.

Finally, we randomly interviewed four managers and ten production workers in the above companies. These people in different positions elaborated their perceptions of the traceability and anticounterfeiting information system and their requirements such as overall functional requirements and specific module requirements, as well as their most concerned aspects. The initial needs were formed and summarized based on these interviews.

3.2. Users' Need for IPTPSCP. Through the above research and interviews, we analyzed and summarized the basic features and key functions of IPTPSCP, as shown in Table 1.

3.3. IPTPSCP Business Flow Analysis. Following the principles of corporate self-discipline, consumer, and government supervision, the needs of different users were fully considered in IPTPSCP to improve the economic benefits and brand effect of enterprises, strengthen government supervision, ensure product quality, and protect consumer rights and interests. IPTPSCP business process analysis is shown in Figure 1.

The above business process consists of the following major steps:

(1) The company provides its information to register in IPTPSCP, which shall be audited by the administrator and certified by a third-party certification body.

(2) After passing the audit and certification, companies can manage basic information such as product names, categories, and specifications.
(3) The enterprise sets up traceability units and nodes for different products and then collects and inputs complete product traceability information.

(4) The administrator audits the authenticity and standardization of product traceability information. After approval, the company can generate product traceability code, anticounterfeiting codes, and other pieces of relevant information and then submit them to third-party certification. After being certified, the above information can be stored in the cloud database.

(5) Consumers can browse and query the traceability and anticounterfeiting information. If problems are found, they can complain about the net and give feedback to government regulators, who will deal with it by relevant laws and regulations.

\section{System Design and Implementation}

4.1. IDcode Coding Rules [13]. Product coding is essential to product traceability and anticounterfeiting. In this paper, the "safe, independent, standardized, and controllable" IDcode two-dimensional code coding system was adopted for product coding. IDcode has passed GB/T 33993-2017 Commodity Two-Dimensional Code Release and is compliant with ISO/IEC 15459 Information Technology-Automatic Identification and Data Acquisition TechnologyUnique Identification. As a mechanism to realize the unified management of various object identifications, IDcode is recognized by ISO, CEN, and AIM. The IDcode coding system has three characteristics:

(1) Identity: every object (person/event/thing) can get a globally unique QR code ID.

(2) Interconnection: a framework for mapping and linking various codes, coding systems, and application systems has been developed. Interconnections among different regions, networks, systems, and codes have been built.

(3) Security control: IDcode coding system provides a safe mobile Internet transaction interaction environment for the public. It serves as an effective, credible information security application tool for enterprises and provides a safe QR code environment for society.

As shown in Figure 2, IDcode coding structure is a tree structure and consists of three parts:

(1) The first part is the user root. It is made up of four nodes. The first root node identifier "MA" is a global code recognized by ISO, CEN, and AIM organizations. The second node is the area code for the region. This code can be found in ISO 3166-1:2013 Code Representation Names of Countries and Its Branches Part 1: Country Codes. The third one is the user code. It is coded by the type of user. The Government Agency User Code is 1001, Code 1002 is for Voluntary Organizations, Code 1003 is for 
TABLE 1: The scientific prototype of IPTPSCP.

IPTPSCP should

(i) Allow users to flexibly set the traceability units and nodes, to meet the changes of the traceability units and nodes caused by the production of different types of products and adjustment of the production process

(ii) Adapt to the settings of different traceability units and nodes in various companies producing a variety of important products

(iii) Realize the efficient integration of hardware automatically collecting data with the software automatically processing the information via the embedded models and knowledge

(iv) Achieve the information traceability of user-defined traceability units and nodes. When product quality or safety issues occur, the smallest error subset can be found and related responsibilities can be defined

(v) Allow users to use mobile phones, computers, and other terminals to inquire information through App, WeChat Mini program, Web, etc., and report problematic companies or products

(vi) Be able to meet the need of supervision of relevant government departments and enable us to expose and punish problematic companies or products

(vii) Have certain anticounterfeiting and antichanneling functions

(viii) Reserve interfaces for future implementation of traceability, anticounterfeiting related big data analytics, and other value-added services

Scientific Research Institutes, and Code 1006 is for Certification Institutions. General enterprises and institutions adopt the administrative division codes of various countries or are coded by each country itself. The node can be extended according to the application requirements. The fourth node is the registration sequence number, arranged in order of application.

(2) The second part is the identification object category, which is divided into two situations: general coding structure and own coding structure. The general coding structure is composed of three nodes, and the number of nodes in the own coding structure is defined by the user.

(3) The third part is the individual code of the custom identification object. The user can customize the number of nodes and the number of bits per node according to the needs of the application.

Special note: the first part and the second part are separated by the punctuation "." or symbol "/," the second part and the third part are separated in the same way, and the nodes in each segment are distinguished by a "."

In this paper, the second part (identification object category) in the IDcode coding adopts a general coding structure, for example, MA.156.441302.1184/10.29034004.01 02/20201214.001, where MA.156.441302.1184 represents the root unit, 10.29034004.0102 represents the category of object, and 20201214.001 represents the individual code of the custom object.

The difference between the $\mathrm{QR}$ code based on IDcode coding system and the ordinary QR code is shown in Table 2.

\subsection{Four-Color $Q R$ Code Generation Algorithm. Ordinary} monochrome QR codes are easily forged if someone knows the link of QR code. Therefore, this paper developed a four-color QR code, which is equivalent to adding a color code to the ordinary $\mathrm{QR}$ code. If the color code corresponding to the $\mathrm{QR}$ code is not known, it cannot be forged in batches. The specific method is as follows. Firstly, the ordinary monochrome QR code is generated via the existing $\mathrm{QR}$ code generation algorithm. Then, we use the prebuilt color library to perform color rendering on the upper left, lower left, upper right, and lower right of the monochrome QR code image to obtain a four-color QR code. There are 7 different colors in the color library, and each color has a color number code; see Table 3 for details. For example, the colorful QR code shown in Figure 3, which is a product anticounterfeiting code of a company in IPTPSCP, is a four-color QR code rendered by the color code sequence "1-3-7-4." Each color QR code image requires approximately $1.12 \mathrm{~K}$ storage space, which takes up very little space. Compared with the black and white QR code, the color QR code is not only beautiful and safer but also does not increase the cost and difficulty of printing or spraying, which is conducive to largescale promotion and application.

The pseudocode of the function for generating a fourcolor QR code is described as follows:

\section{Function Generate Four Color QRCode(string) \{}

Using Google's ZXing library to generate monochrome QR codes;

Randomly generate 4-digit color code (each digit is different from the others);

Traverse each pixel in the monochrome QR code image \{

if (pixel position $<$ image width/2 \&\& pixel position$<$ image height/2), then set the pixel color to the color represented by the color code of the first digit;

if (pixel position $<$ image width/2 \&\& pixel position$\geq$ image height/2), then set the pixel color to the color represented by the color code of the second digit;

if (pixel position $\geq$ image width/2 \&\& pixel position$<$ image height/2), then set the pixel color to the color represented by the color code of the third digit;

if (pixel position $\geq$ image width/2 \&\& pixel position$\geq$ image height $/ 2$, then set the pixel color to the color represented by the color code of the fourth digit.

\}

Return to the four-color QR code image. 


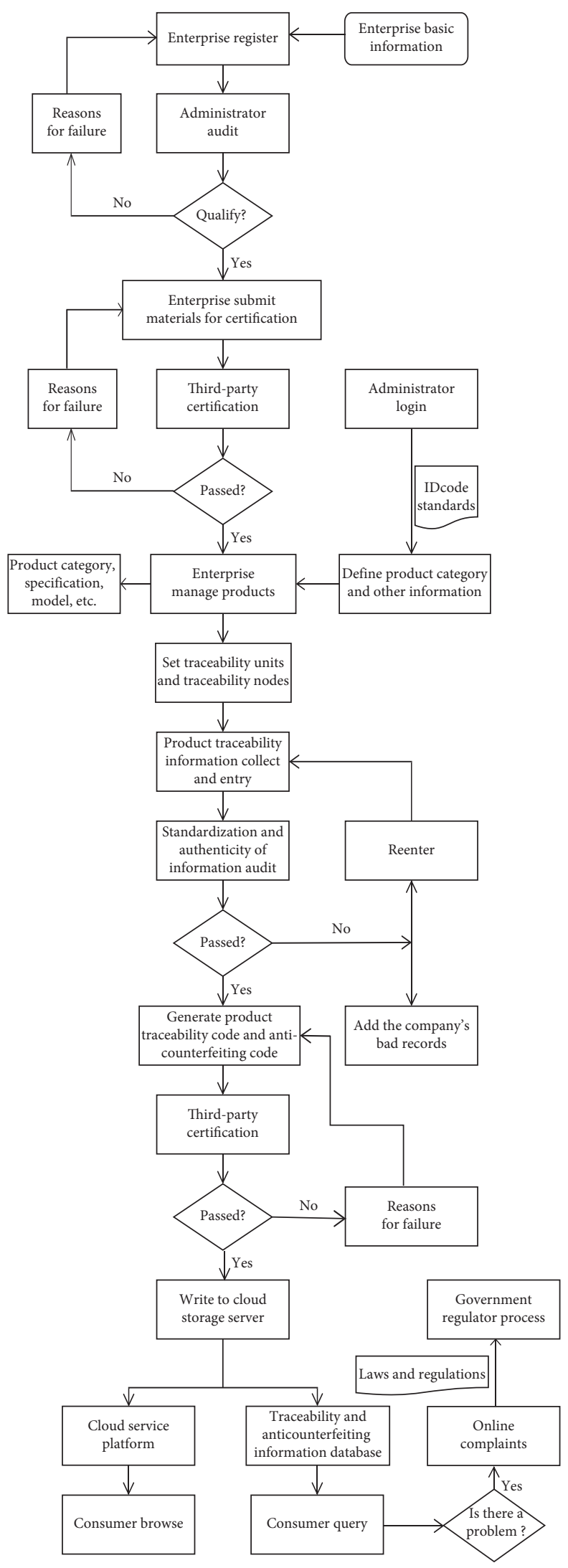

FIGURE 1: IPTPSCP business flowchart. 


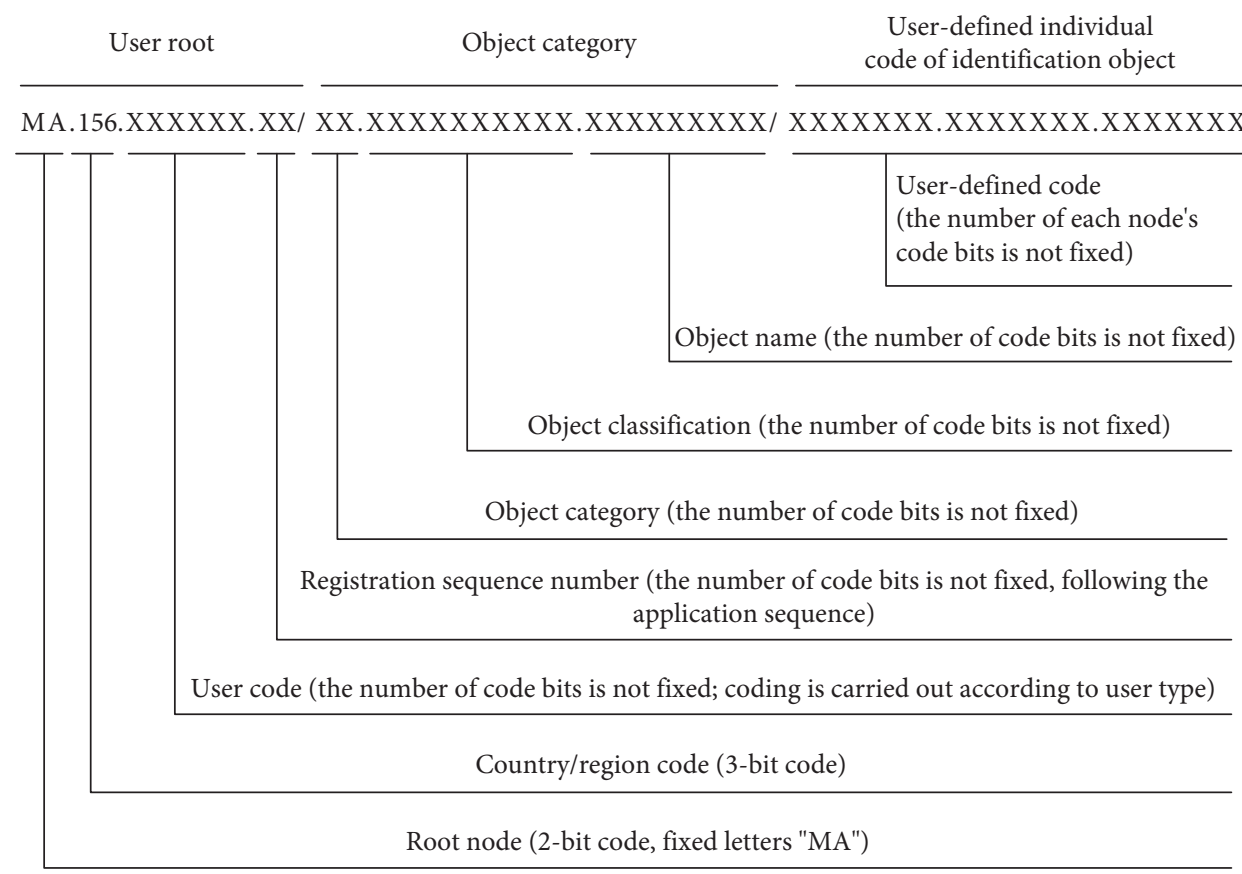

FIGURE 2: Schematic diagram of two-dimensional code identification coding data structure (general coding structure).

TABLE 2: Difference between QR code based on IDcode coding system and the ordinary QR code.

\begin{tabular}{lcc}
\hline Comparison items & Ordinary QR code & QR code based on IDcode \\
\hline Product identification & $\checkmark$ & $\checkmark$ \\
Traceability and other extended applications & $\checkmark$ & $\checkmark$ \\
Unified identification mechanism & & $\checkmark$ \\
Compatible with multiple coding systems & & $\checkmark$ \\
Safe and reliable & & $\checkmark$ \\
Internationally recognized and accepted & $\checkmark$ & $\checkmark$ \\
Low cost & & $\checkmark$ \\
Forming standards & & $\checkmark$ \\
\hline
\end{tabular}

TABLE 3: Color library.

\begin{tabular}{|c|c|c|c|}
\hline Code & Color & RGB & Template \\
\hline 1 & Black & $\left(\begin{array}{lll}0 & 0 & 0\end{array}\right)$ & \\
\hline 2 & Red & 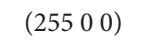 & \\
\hline 3 & Green & $\left(\begin{array}{l}0 \\
0\end{array} 2550\right)$ & \\
\hline 4 & Blue & $\left(\begin{array}{lll}0 & 0 & 255\end{array}\right)$ & \\
\hline 5 & Dark red & $\left(\begin{array}{l}131 \\
27\end{array} 31\right)$ & \\
\hline 6 & Dark green & (8 98 51) & \\
\hline 7 & Orange & $\left(\begin{array}{l}255 \\
165\end{array}\right)$ & \\
\hline
\end{tabular}

4.3. IPTPSCP Technical Architecture. IPTPSCP clients can be divided into web client and mobile client. Consumers can query information by entering the traceability code and anticounterfeiting code string on the web client or scan the QR code image on the mobile client for product traceability and anticounterfeiting queries. The web client and the mobile client are just different in presentation, and the logic of the data layer and business layer is roughly the same. The IPTPSCP technical framework is shown in Figure 4.
4.3.1. Data Layer. The main function of the data layer is to provide storage for structured and unstructured information. The structured data was stored in the MySql database, the unstructured data was stored in the corresponding system in the form of files, and its path was stored in the database system. For various data, different database servers were used for storage; thereby, a database service group was built. For example, a Redis cache database server was set up to improve system access speed, while a warehouse server that stores both structured and unstructured data was constructed to realize multidimensional data analysis and data mining.

4.3.2. Business Layer. The business layer is mainly composed of IPTPSCP core business logic and unified control components. The former mainly refers to the realization of related businesses, including platform management, enterprise management, and service provider management; the latter mainly refers to the realization of auxiliary functions, such as unified authority control, unified log and audit management, unified system backup and recovery, unified exception handling and alarm management, and 


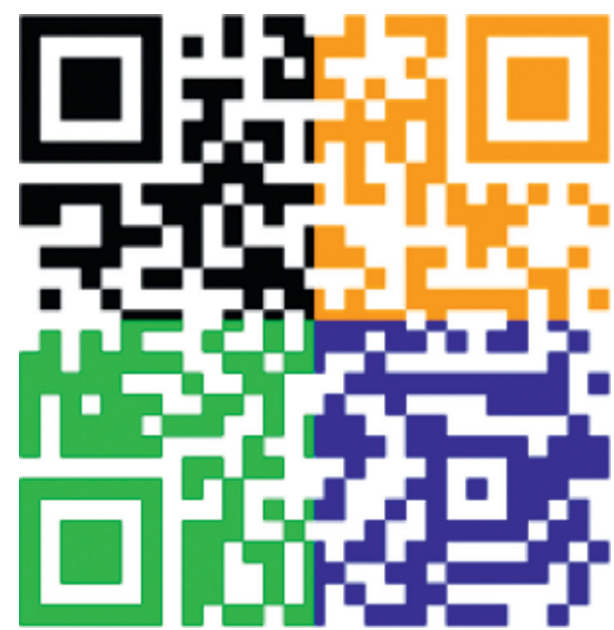

FIgURE 3: An example of four-color QR code.

unified external interface management. They are the basis for the safe operation of the system data and provide conditions for the function expansion of the system. What needs to be pointed out is that using the cloud snapshot service provided by Ali Cloud, a perfect data backup and recovery scheme, was built to avoid data loss caused by sudden failure, system poisoning, or human error.

4.3.3. Control Layer. The control layer is used to process the business related to the access interface; a series of advanced technologies were adopted to ensure that IPTPSCP can still operate efficiently and stably in a high concurrent access status. The purpose of caching is to improve the system access speed and increase the capacity of system processing. Degradation means that when the service has a problem or the service affects the performance of the core process, it needs to be temporarily blocked and restarted after the peak disappears or the problem is solved. Current limiting and asynchronous locking protect the system by limiting the rate and locking of concurrent access or requests, respectively. Restful API is used to achieve front and back end separation, system traffic reduction, and server performance optimization and to prevent security issues such as injection attacks.

4.3.4. Forwarding Layer. The forwarding layer realizes the clustering of application deployment through the combination of hard load and soft load processing. By setting up a backup and establishing a dynamic expansion mechanism, the service provided by the system for users is no longer restricted by the existing resources, and they can be continuously searched and expanded for service resources outside the system. Nginx acts as a proxy server (reverse proxy), forwarding requests from users to different servers, to avoid excessive pressure on the unit server. Static resource CDN acceleration refers to distributing static resources to servers located in computer rooms in multiple geographic locations to achieve nearby access to data, thereby improving access speed.
4.3.5. Application Layer. The application layer is the user GUI access interface. All kinds of users can access IPTPSCP through $\mathrm{H} 5$ official website, enterprise App, Platform App, enterprise WeChat Mini program, platform WeChat Mini program, PC official website, etc.

4.4. IPTPSCP Network Topology. IPTPSCP was designed using B/S architecture based on the cloud service model, as shown in Figure 5. The basic product traceability information was automatically collected or entered in the LAN of the production enterprise. After the relevant business processing of the system, the traceability and anticounterfeiting related text information and $\mathrm{QR}$ code image information were uploaded to the Ali Cloud database server and Qiniu Cloud storage server via the Internet. Moreover, the system was connected to the data control center of the government supervision department to provide traceability, anticounterfeiting inquiry, and management services for enterprises, consumers, the public, and system managers. The function of the firewall is mainly to discover and deal with the security risks and data transmission problems that may exist during system operation in time.

In each enterprise LAN, the integration of different data acquisition hardware equipment (or devices) with IPTPSCP is crucial. Generally, data acquisition hardware equipment is divided into three types: interface equipment, reserved standard interface equipment, and equipped with dedicated software equipment [36]. The schemes of integrating the three equipment with IPTPSCP are described as follows.

4.4.1. Interface Equipment. This type of equipment does not have any interface and usually only provides observation readings. Therefore, the simplest way to deal with this type of equipment is to provide a pure software entry interface.

4.4.2. Reserve Standard Interface Equipment. Most of these types of equipment have RS232 serial ports or parallel ports, and the parallel ports can be converted into serial ports through customized wiring. There are two mainstream methods for the integration of serial equipment: direct integration and integration by using serial ports server.

4.4.3. Equipped with Dedicated Software Equipment. The characteristic of this type of equipment is that the data has been collected and stored in the workstation, but the storage format is different, usually divided into three types: standard text file format, standard database storage format, and encrypted format. The data collection and integration of this type of equipment can generally be divided into three steps: interception, analysis, and forwarding.

\section{System Application and Evaluation}

5.1. Case Selection. As an example, a detailed tracking research has been made in a tea production enterprise (abbreviated as enterprise A) in Xinyang city, Henan province, China. Company $\mathrm{A}$ is mainly engaged in the 


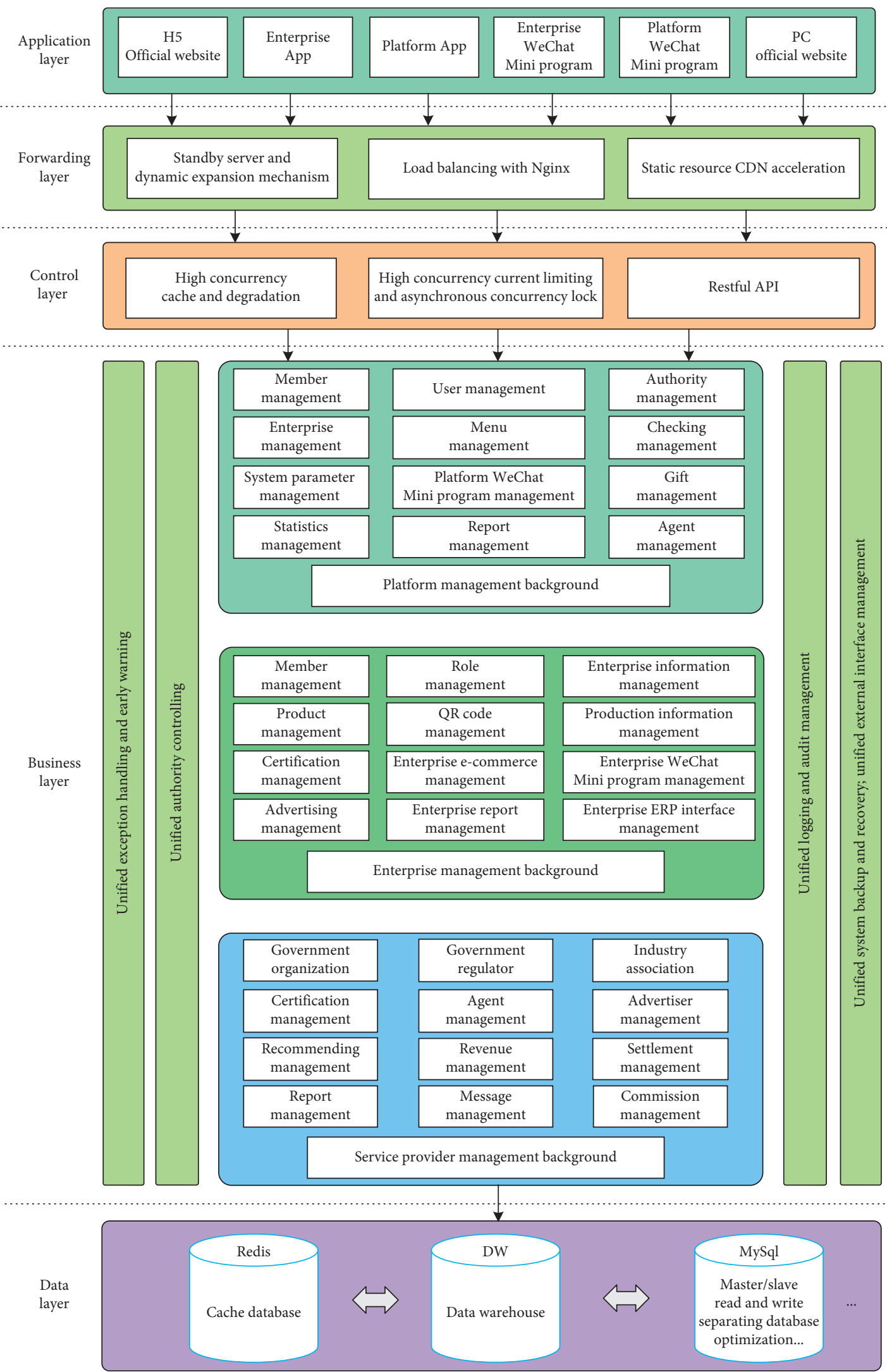

FigURE 4: IPTPSCP technical architecture diagram. 


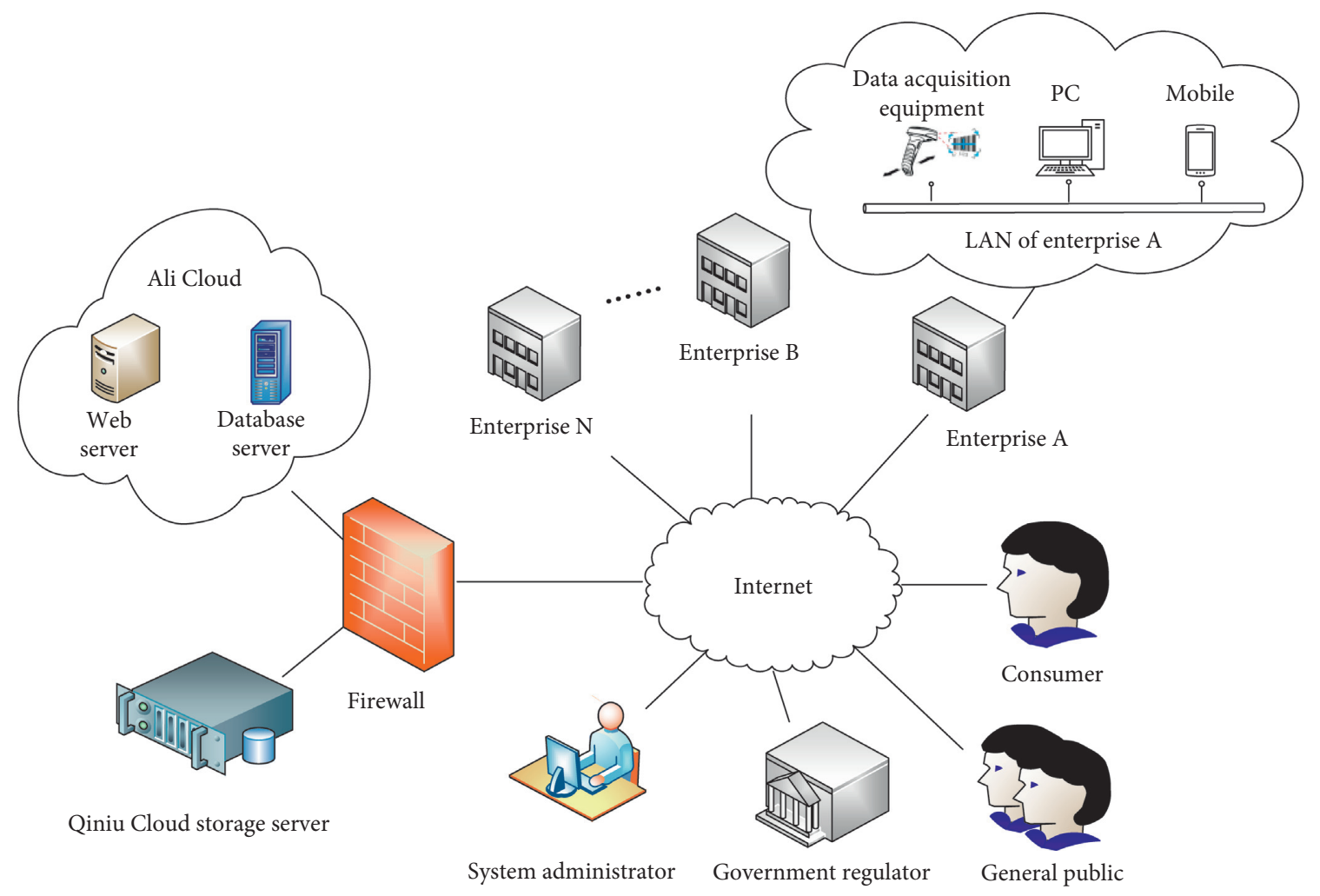

FIgURE 5: IPTPSCP network topology diagram.

processing and sales of Xinyang Maojian green tea, which is one of the top ten famous teas in China. In view of the actual processing and sales of Xinyang Maojian of company A, five traceability units of fresh leaf purchase, processing, packaging, finished product (storage), and sales were selected to record the key information of product circulation. The processing unit is a mechanized operation, which mainly includes screening, spreading, green removing, winnowing, moisture restoration, rolling, carding, and baking. Among them, the four processes of screening, green removing, carding, and baking are important processes that determine the quality and safety of tea. Therefore, after careful consideration and weighing of various influencing factors, company A set the four processes of screening, green removing, carding, and baking as the traceability nodes of the processing unit. In IPTPSCP, the smallest traceability granularity can be flexibly set according to user needs. And each item in data code design has only one code, and one code marks one item. On this basis, according to different packaging carriers, the twolevel concatenated code and three-level concatenated code may be set, so as to realize the multilevel association of different packaging carriers.

5.2. System Application. After passing the registration and authentication, enterprise A becomes the IPTPSCP user.
First, the administrators of company A set the traceability units and nodes in the IPTPSCP. As shown in Figure 6, the purchase unit, packaging unit, finished product (storage) unit, and sales unit were each equipped with one traceability node, while the processing unit has four traceability nodes. Figure 7 clearly shows the logical sequence of each traceability node.

Then, the operator can automatically collect or enter the relevant information of each traceability node of the above five traceability units into the system. Taking the processing unit as an example, the information of each traceability node is shown in Figure 8.

Subsequently, the operator can generate the color traceability QR code and the anticounterfeiting QR code, as shown in Figure 9.

Figure 10 is an example of the traceability QR code and anticounterfeiting $\mathrm{QR}$ code of a certain specification and batch of Xinyang Maojian tea that have been issued and passed the certification. Consumers can obtain product traceability or anticounterfeiting information by scanning the QR code or inputting the traceability code or anticounterfeiting code string, as shown in Figures 11 and 12, respectively.

5.3. System Evaluation. System evaluation measures the current performance and provides the basis for future 


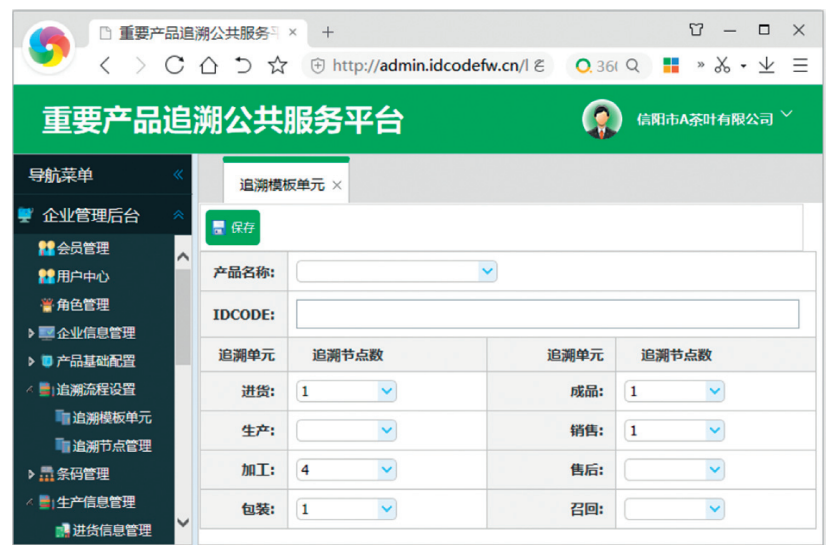

Figure 6: Setting up tracing units and tracing nodes.

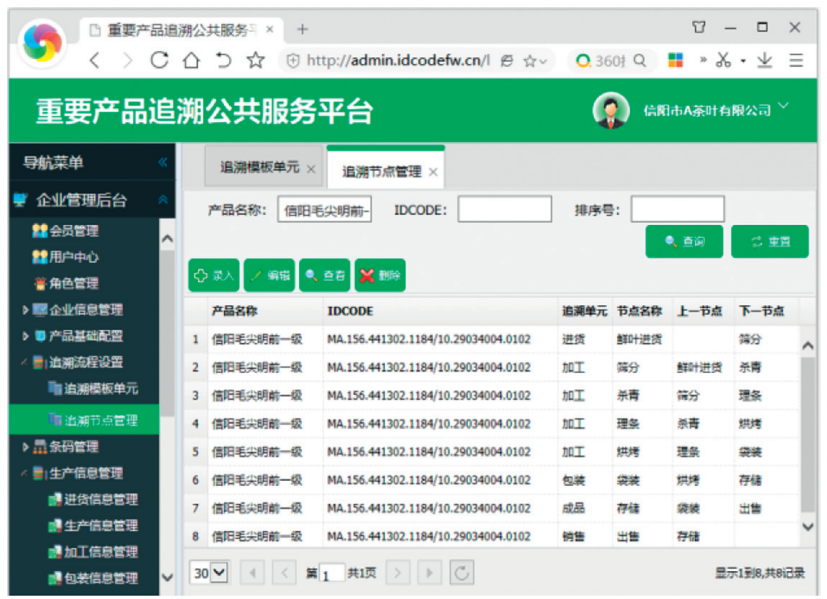

Figure 7: Logical sequence of tracing nodes.

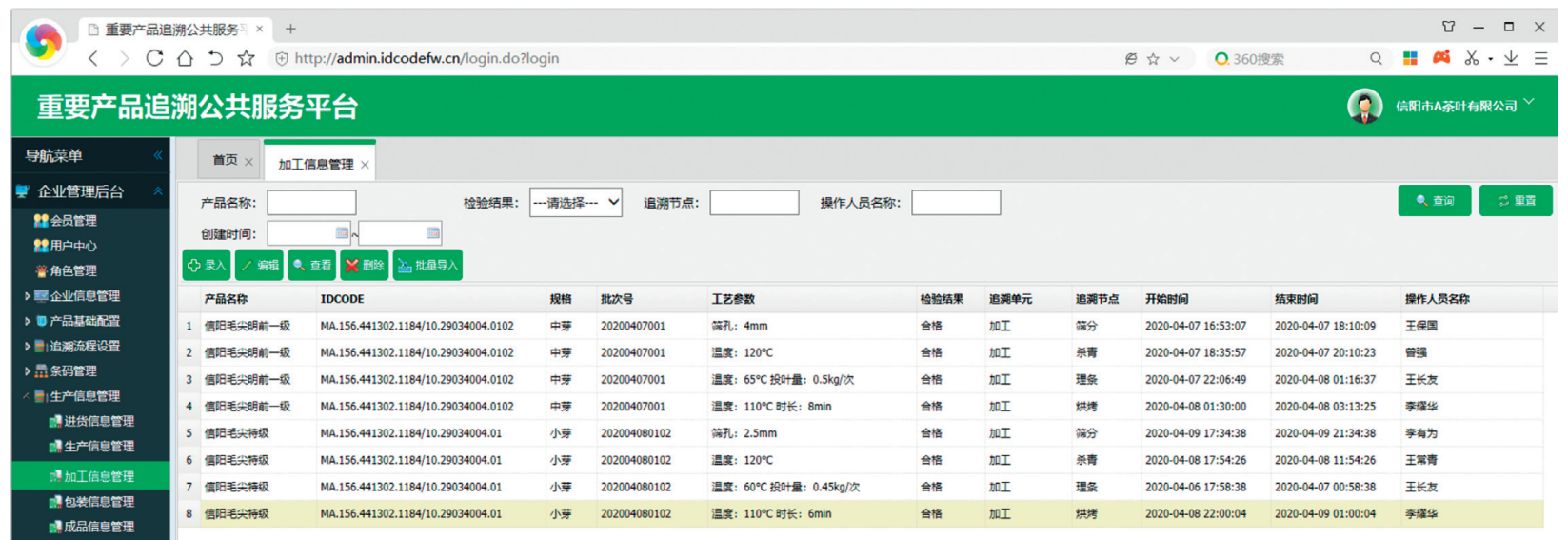

FIGURE 8: Information collection or entry for processing unit. 


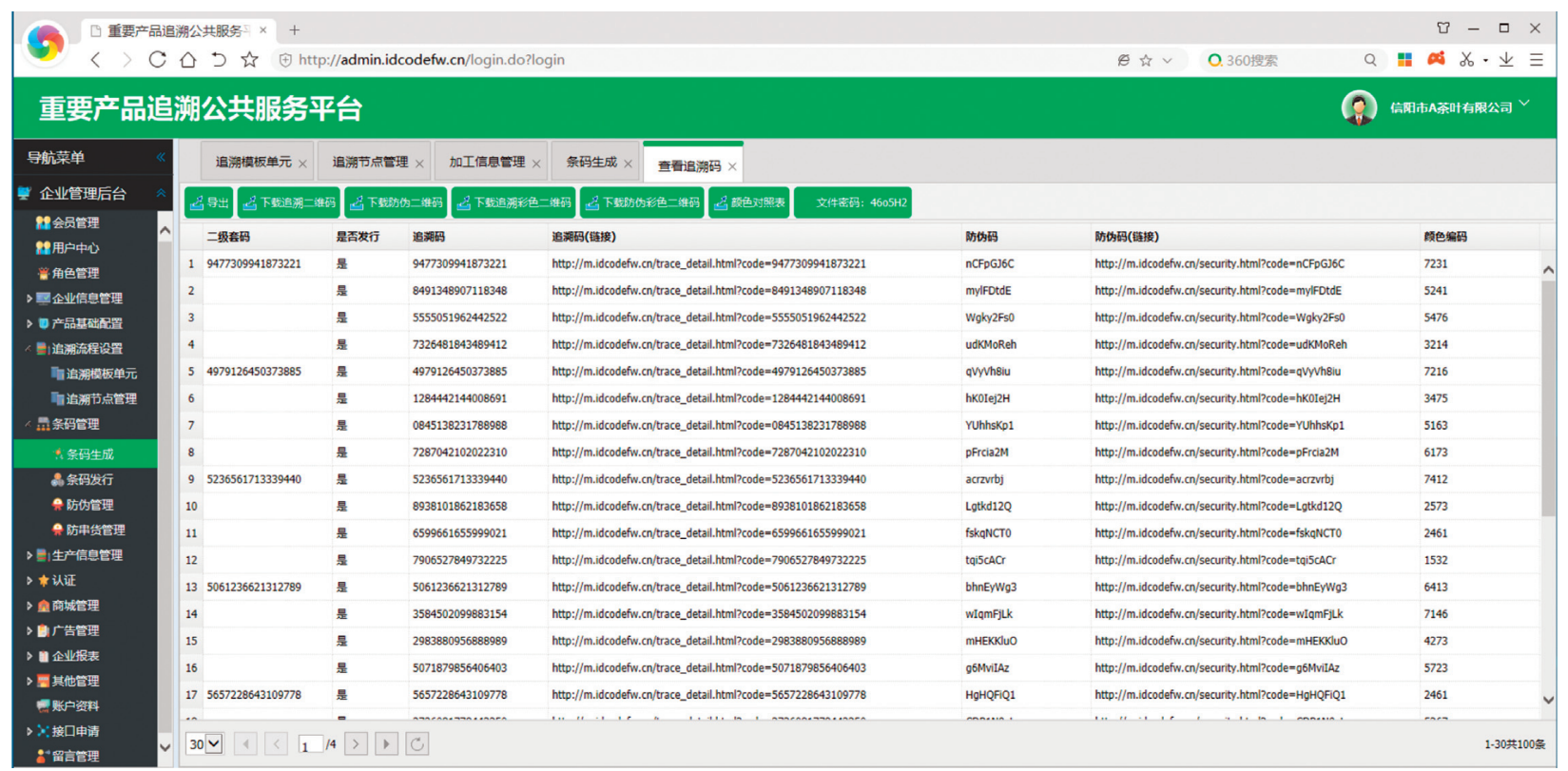

FIGURE 9: Generation of tracing code and anticounterfeiting code.

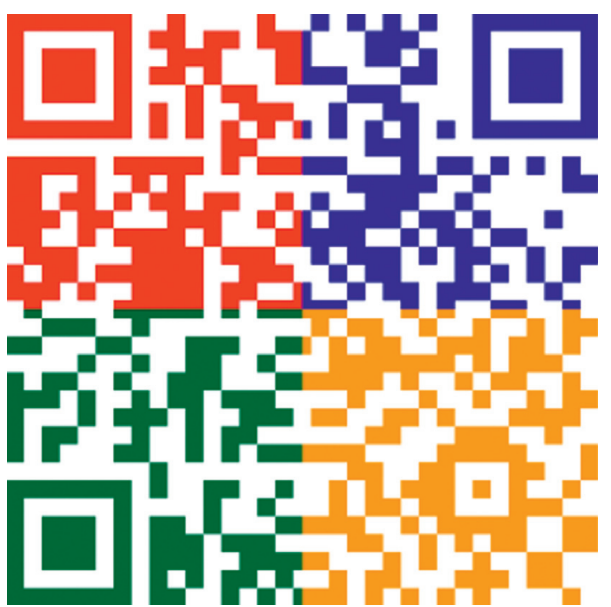

(a)

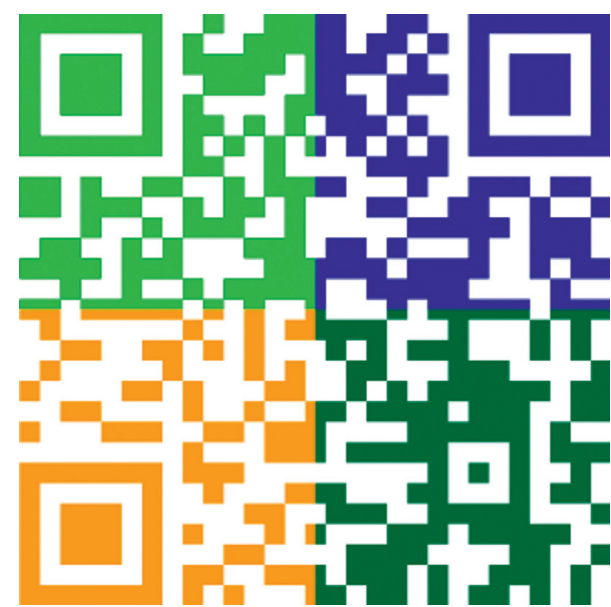

(b)

Figure 10: Example of traceability QR code (a) and anticounterfeiting QR code (b).

improvement of the IPTPSCP. The system evaluation of IPTPSCP was implemented after it ran normally for 11 months (from March 2020 to January 2021) to estimate the technological capacity, performance, and system utilization. Three researchers from Guangdong University of Technology and five specialists from the platform settled enterprises (including enterprise A) were invited to participate in an evaluation committee in order to draw up an evaluation framework for IPTPSCP based on the views of system development and maintenance, user experience, and external influences.

System evaluation was divided into three main steps. Firstly, the evaluation content (including qualitative and quantitative indicators) was determined. Then, the relevant data (including the data collected by the evaluators and the data automatically recorded by IPTPSCP) were organized and analyzed. Finally, the evaluators tested the platform, discussed the implementation effects of IPTPSCP, and gave the evaluation results. The effectiveness analysis before and after IPTPSCP implementation is shown in Table 4. The evaluators also analyzed and suggested some changes for IPTPSCP. The system improvement suggestions included (1) traceability information security on Web, App, and WeChat Mini program, (2) load balancing during concurrent access by multiple users, and (3) fine-tuning of the system menu and GUI interface design. 


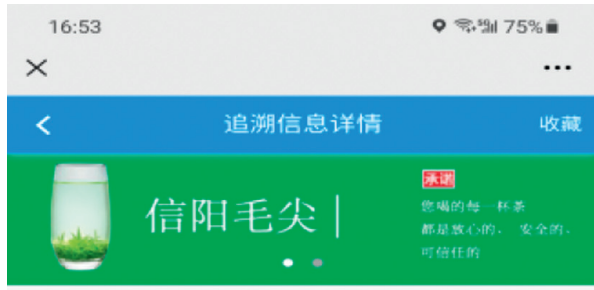

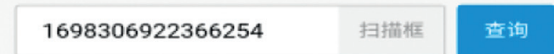

追溯环节

进货环节进货

节点名称鲜叶进货

供应商名称农户A

检验结果合格

检验人李緬华

检验日期 2020-04-07 2020-04-07

加工环节加工

节点名称留分

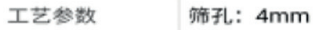

检验结果合格

检验人王保国

检验日期 2020-04-07 2020-04-07

加工环节加工

节点名称杀青

FIgURE 11: Example of traceability information (partial).

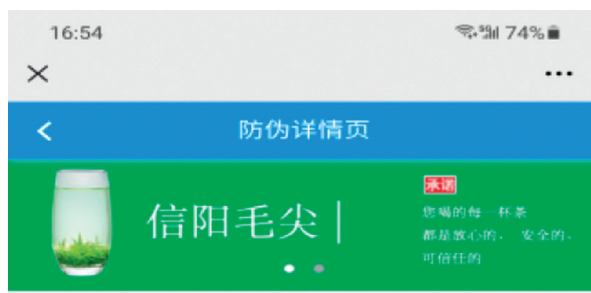

防伪信息

企业名称信阳市A荣叶有限公司【点击查看】

产品名称信阳毛尖明前一级

销售区域信阳市

产品查询次数 6

首次查询时间 2020-12-22 21:27:06

产品IDcode码 MA.156.441302.1184/10.29034004.1

防伪页非首次查询。

\section{平台超链接}

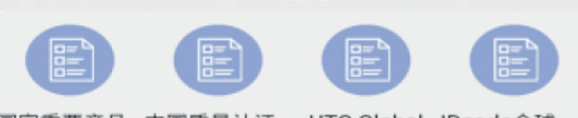

国家重要产品...中国质量认证... UTC Global IDcode全球...

FIGURE 12: Example of anticounterfeiting information. 
TABLE 4: Effectiveness analysis before and after IPTPSCP implementation.

\begin{tabular}{|c|c|c|c|}
\hline No. & Content & Before IPTPSCP implementation & After IPTPSCP implementation \\
\hline 1 & Management precision & Day/week & Minute/second \\
\hline 2 & Data acquisition & Incomplete artificial collection & Automatic or semiautomatic collection \\
\hline 3 & Traceability & Fuzzy & Precise positioning \\
\hline 4 & Anticounterfeiting & None & Accurately identify the authenticity of goods \\
\hline 5 & Antifleeing & None & Good prevention of fleeing goods \\
\hline 6 & Quality analysis & Empirically with delay & Accurate, real time \\
\hline 7 & Multidimensional statistical analysis & None & Multidimensional data analysis based on data warehouse \\
\hline 8 & $\begin{array}{c}\text { Development and deployment } \\
\text { efficiency }\end{array}$ & None & $\begin{array}{l}\text { Code reusable, mature software framework, cloud service } \\
\text { model }\end{array}$ \\
\hline 9 & Maintainability & None & Modularity, replaceable code, and nodes \\
\hline 10 & User-friendliness & None & Well-designed interface, easy to use \\
\hline 11 & Information security & $\begin{array}{l}\text { Paper archives, easily damaged or } \\
\text { lost }\end{array}$ & Database backup and recovery \\
\hline 12 & Information sharing & Producer only & Producer, consumers, and government regulators \\
\hline 13 & Average response time & None & $<0.6$ second \\
\hline 14 & Number of concurrent users & None & $\geq 1000$ \\
\hline 15 & Queries per second & None & $>2600$ \\
\hline
\end{tabular}

\section{Discussion and Conclusions}

IPTPSCP that utilizes QR code technology provides a significant opportunity to ensure production quality and safety. This paper analyzed the business flow of IPTPSCP and elaborated the development and implementation of IPTPSCP. Compared with the traditional system, IPTPSCP achieves a cross-communication information flow between managers, workers, consumers, and government regulators. The system test and experiment evaluation proved itself as an effective production quality management tool that leads to a flexible setting of various production workflow monitoring and recording. And now, IPTPSCP has been successfully applied in many enterprises.

To apply IPTPSCP, enterprises do not need to invest a lot of software development, deployment, and maintenance costs. Enterprises only need to invest a small amount of money to purchase or develop some hardware for data acquisition. Through the interviews and statistical analysis of the system implementation of more than 10 enterprises stationed in IPTPSCP, it can be obtained that the overall efficiency of data collection and monitoring has increased by about $13 \%$, and the cost has been reduced by about $36 \%$. As a result, IPTPSCP does not only increase economic benefits for enterprises but also improve consumer confidence in production quality and safety. Moreover, it also provides convenient conditions for government regulators to conduct product quality and safety supervision.

This work can be extended for future research in many directions. For example, IPTPSCP is expected to be integrated into an e-commerce system, which enables consumers to query the traceability information of the selected product in real time when shopping online. The author's team has begun preliminary work on this subject. In addition, with the evergrowing and changing data in the IPTPSCP, a big data analysis platform can be built to provide enterprises, consumers, and government regulators with indepth value-added services, such as product brand analysis, analysis, and mining of industry data. This will be a very meaningful thing.

\section{Data Availability}

No data were used in this study.

\section{Conflicts of Interest}

The authors declare that they have no conflicts of interest.

\section{Acknowledgments}

The authors would like to acknowledge the support from Huizhou University Scientific Research Special Fund Project (IOT Information Technology Laboratory Project, no. 20180407).

\section{References}

[1] M. M. Aung and Y. S. Chang, "Traceability in a food supply chain: safety and quality perspectives," Food Control, vol. 39, pp. 172-184, 2014.

[2] T. Kelepouris, K. Pramatari, and G. Doukidis, "RFID-enabled traceability in the food supply chain," Industrial Management \& Data Systems, vol. 107, no. 1-2, pp. 183-200, 2007.

[3] L. Tarjan, I. Šenk, S. Tegeltija, S. Stankovski, and G. Ostojic, "A readability analysis for QR code application in a traceability system," Computers and Electronics in Agriculture, vol. 109, pp. 1-11, 2014.

[4] Y. Cao, X. Liu, C. Guan, and B. Mao, "Implementation and current status of food traceability system in Jiangsu China," Procedia Computer Science, vol. 122, pp. 617-621, 2017.

[5] M. Heyder, L. Theuvsen, and T. Hollmann-Hespos, "Investments in tracking and tracing systems in the food industry: a PLS analysis," Food Policy, vol. 37, no. 1, pp. 102-113, 2012. 
[6] D. Paunescu, W. J. Stark, and R. N. Grass, "Particles with an identity: tracking and tracing in commodity products," Powder Technology, vol. 291, pp. 344-350, 2016.

[7] T. Pizzuti and G. Mirabelli, "The global track \& trace system for food: general framework and functioning principles," Journal of Food Engineering, vol. 159, pp. 16-35, 2015.

[8] H. Bai, G. Zhou, Y. Hu et al., "Traceability technologies for farm animals and their products in China," Food Control, vol. 79, pp. 35-43, 2017.

[9] J. Qian, X. Du, B. Zhang, B. Fan, and X. Yang, "Optimization of QR code readability in movement state using response surface methodology for implementing continuous chain traceability," Computers and Electronics in Agriculture, vol. 139, pp. 56-64, 2017.

[10] B. Fan, J. Qian, X. Wu et al., "Improving continuous traceability of food stuff by using barcode-RFID bidirectional transformation equipment: two field experiments," Food Control, vol. 98, pp. 449-456, 2019.

[11] S. Violino, F. Pallottino, G. Sperandio et al., "A full technological traceability system for extra virgin olive oil," Foods, vol. 9, no. 5, p. 624, 2020.

[12] R. Badia-Melis, P. Mishra, and L. Ruiz-García, "Food traceability: new trends and recent advances. a review," Food Control, vol. 57, pp. 393-401, 2015.

[13] ZIIOT, International Two-imensional Code Object Identifier System (IDcode) White Papers, 2018, http://www.ziiot.org.cn/ Web/Content.aspx? $\mathrm{c}=797 \& \mathrm{~m}=280$.

[14] P. Olsen and M. Borit, "How to define traceability," Trends in Food Science \& Technology, vol. 29, no. 2, pp. 142-150, 2013.

[15] T. Moe, "Perspectives on traceability in food manufacture," Trends in Food Science \& Technology, vol. 9, no. 5, pp. 211-214, 1998.

[16] F. Dabbene, P. Gay, and C. Gay, "Traceability issues in food supply chain management: a review," Biosystems Engineering, vol. 120, pp. 65-80, 2014.

[17] J. A. Alfaro and L. A. Rábade, "Traceability as a strategic tool to improve inventory management: a case study in the food industry," International Journal of Production Economics, vol. 118, no. 1, pp. 104-110, 2009.

[18] N. Mai, S. Gretar Bogason, S. Arason, S. Víkingur Árnason, and T. Geir Matthíasson, "Benefits of traceability in fish supply chains-case studies," British Food Journal, vol. 112, no. 9, pp. 976-1002, 2010.

[19] J.-P. Qian, X.-T. Yang, X.-M. Wu, L. Zhao, B.-L. Fan, and B. Xing, "A traceability system incorporating $2 \mathrm{D}$ barcode and RFID technology for wheat flour mills," Computers and Electronics in Agriculture, vol. 89, pp. 76-85, 2012.

[20] X. Wang, D. Fu, G. Fruk, E. Chen, and X. Zhang, "Improving quality control and transparency in honey peach export chain by a multi-sensors-managed traceability system," Food Control, vol. 88, pp. 169-180, 2018.

[21] L. Qi, J. Zhang, M. Xu, Z. Fu, W. Chen, and X. Zhang, "Developing WSN-based traceability system for recirculation aquaculture," Mathematical and Computer Modelling, vol. 53, no. 11-12, pp. 2162-2172, 2011.

[22] G. Alfian, J. Rhee, H. Ahn et al., "Integration of RFID, wireless sensor networks, and data mining in an e-pedigree food traceability system," Journal of Food Engineering, vol. 212, pp. 65-75, 2017.

[23] Y. Q. Peng, L. X. Zhang, Z. X. Song, J. Yan, X. X. Li, and Z. B. Li, "A QR code based tracing method for fresh pork quality in cold chain," Journal of Food Process Engineering, vol. 41, no. 4, Article ID e12685, 2018.
[24] G. D. Gao, K. Xiao, and M. M. Chen, "An intelligent IoTbased control and traceability system to forecast and maintain water quality in fresh water fish farms," Computers and Electronics in Agriculture, vol. 166, Article ID 105013, 2019.

[25] S. S. Hu, S. Huang, J. Huang, and J. F. Su, "Blockchain and edge computing technology enabling organic agricultural supply chain: a framework solution to trust crisis," Computers \& Industrial Engineering, vol. 153, Article ID 107079, 2021.

[26] K. M. Karlsen, K. A.-M. Donnelly, and P. Olsen, "Granularity and its importance for traceability in a farmed salmon supply chain," Journal of Food Engineering, vol. 102, no. 1, pp. 1-8, 2011.

[27] J. Hu, X. Zhang, L. M. Moga, and M. Neculita, "Modeling and implementation of the vegetable supply chain traceability system," Food Control, vol. 30, no. 1, pp. 341-353, 2013.

[28] M. Thakur and K. A.-M. Donnelly, "Modeling traceability information in soybean value chains," Journal of Food Engineering, vol. 99, no. 1, pp. 98-105, 2010.

[29] T. B. Chen, K. F. Ding, S. K. Hao et al., "Batch-based traceability for pork: a mobile solution with $2 \mathrm{D}$ barcode technology," Food Control, vol. 107, Article ID 106770, 2020.

[30] K. Liang, X. Chen, R. He et al., "Development and parameter optimization of automatic separation and identification equipment for grain tracing systems based on grain tracers with QR codes," Computers and Electronics in Agriculture, vol. 162, pp. 709-718, 2019.

[31] Y. Cai, X. W. Li, R. M. Wang, Q. Yang, P. Li, and H. Hu, "Quality traceability system of traditional Chinese medicine based on two dimensional barcode using mobile intelligent technology," PLoS One, vol. 11, no. 10, Article ID e0165263, 2016.

[32] B. D. Li, Y. Yang, J. F. Su, N. Zhang, and S. Wang, "Two-sided matching model for complex product manufacturing tasks based on dual hesitant fuzzy preference information," Knowledge-Based Systems, vol. 186, Article ID 104989, 2019.

[33] E. A. Fernandes, G. A. Sarriés, M. A. Bacchi, Y. T. Mazola, C. L. Gonzaga, and S. R. V. Sarriés, "Trace elements and machine learning for Brazilian beef traceability," Food Chemistry, vol. 333, Article ID 127462, 2020.

[34] Y.-S. Bong, J.-S. Ryu, S.-H. Choi, M.-R. La, and K.-S. Lee, "Investigation of the geographical provenance of the beer available in South Korea using multielements and isotopes," Food Control, vol. 60, pp. 378-381, 2016.

[35] H. Zhao, S. Zhang, and Z. Zhang, "Relationship between multi-element composition in tea leaves and in provenance soils for geographical traceability," Food Control, vol. 76, pp. 82-87, 2017.

[36] J. Tang, "Research and implementation of a data acquisition scheme for heterogeneous device interfaces," Software Engineering, vol. 20, no. 5, pp. 36-39, 2017. 